\title{
Funding University Forest Research
}

by

G. F. Weetman'

\section{Introduction}

The lack of forest research at the six Canadian forestry schools and the related lack of strong graduate programmes are of great concern to the Universities. There are very few Canadian PhDs in forestry and it is extremely difficult to hire Canadian scientists and professors in forestry.

One of the chief sources of funding for scientific research in Canada is the Natural Sciences and Engineering Research Council (NSERC). NSERC provides research grants for professors via the University; the professors receive no salaries. Grants are provided for one to three year periods. The use of the grants is entirely at the discretion of the professors, following guidelines established by NSERC. The Universities administer the funds. Application is made annually by the professors to NSERC. The grant applications are sent out for anonymous peer review. The decision on the amount and length of funding is made by committees primarily composed of professors who serve voluntary three year terms. The expenses of the committees are paid by NSERC, which has a staff of about 70 people.

The committee members go on "site visits" to universities across Canada to meet with the applicants and the University administrators. All of the committees meet simultaneously in the National Conference Centre in Ottawa in February for 5 days. During this period of intense activity each committee assigns its limited budget of grant money to the applicants. There are about 30 committees covering all branches of Natural Sciences and over 300 professors are involved: social sciences, arts and medical sciences are handled by separate granting bodies.

The system is a national one and is highly competitive and very rigorous. In order to compete publication in refereed journals is essential, in addition applicants must propose scientific work that the committee, composed of their peers, feels is sound and of interest. There are really no other criteria.

Professors are completely free to pursue any topic that they please. Relevance to present government or industry concerns is not required; nor does politics enter. There are special grants for 'strategic areas' i.e. areas identified as being of great concern. Forestry is not one of them. There is no special committee for forestry, nor is there one for agriculture.

Success in receiving NSERC grant applications is, because of its rigour and independent assessment, used by university administrators as an important criteria in promotion, salary, tenure and space assignments of individual professors. This is where "publish or perish" becomes a reality.

\section{Comments in Current Funding Problems}

There are 3 or 5 forestry professors scattered about the NSERC committees at any one time. The attached notes were prepared after a 3 year stint in the Plant Biology Committee - a committee which receives many of the 'forestry' grant applications. These comments are entirely personal and do not reflect any NSERC or University policy.

\footnotetext{
${ }^{1}$ Faculty of Forestry, University of British Columbia, Vancouver, BC, V6T 1W5
}

1. The usual arguments between funding excellence in science and building or supporting science, done by professors under very difficult circumstances (small University, heavy teaching loads, etc.), were tossed around. In reality only excellence is recognized, provided it is associated with publication and creates "excitement" in the Committee.

2. The competition for funding among the 170 applicants was very severe and the sizes of the awards were low ( $\$ 6$ to 55,000$)$ in relation to current salary levels. Increasingly NSERC appears to be a mechanism to recognize scientific capability, but is not a mechanism for adequate funding. The frustration and even bitterness of the professors over the deteriorating situation for funding science in Canada was evident.

3. New applicants get a favourable treatment and an opportunity to prove themselves if they submit a good application. Applications must reflect a thorough understanding and awareness of contemporary research in the field. Funding range $\$ 8-16,000$.

4. I see no evidence that forestry applications are not receiving as a fair treatment by the Committee as other disciplines. The onus is upon the applicant to convince a mixed group of scientists that the proposal is sound. The creation of a separate "Forestry" Committee would only mean a wide diversity of forestry scientists had to be convinced. The advantage of a separate forestry committee might be a budgeted amount for "Forestry". This would be great if the budgeted amount was great, however, this would be very unlikely. When a major volume of "Forestry" applications are submitted a separate committee may be justified.

5. The Canadian Forestry Schools cannot really consider NSERC Operating Grants as very significant source of funding for forest research because:

(a) Most of the present operating grant holders are locked in at low funding levels.

(b) Once out of the system, or without an adequate current publication record, it is very difficult to get back onto the system.

(c) Continued vigilance is required by each applicant to his publications and quality of application; relaxation for whatever reason (administration, foreign assignment, contract work, professional obligations, heavy teaching loads, etc.) will result in the loss of the grant. The committee is quite merciless because of the intense competition for funding and the continued pressure of fresh PhD's.

(d) Most forestry professors in Canada are "one deep" in their fields, have heavy teaching loads, and often heavily involved in a wide range of legitimate non-scientific activities - often not by choice, but often by force of circumstances in their undermanned disciplines.

6. The mechanism for Canadian Forestry Schools to expand their NSERC Operating Grant Funding are set by the system itself; these are:

(a) Hire fresh PhD's with good scientific training and have them put in a good application as soon as they have a publication record; if successful they must be free to work on forest science, in return 
the applicants must do their damnedest to understand the system and put in good applications (the pervasive reputation of forestry for poor applications is real).

(b) Try to build around an established scientific strength in the schools, i.e. Post Docs, University Research Fellows, Technician Support, Equipment and new PhD's whenever discretionary funds are available (A very good use for Block Grant dollars).

(c) Beg, borrow or steal established scientists and put them in the Forestry Schools (use adjunct Professors, Sabbatical leave scientists, exchange fellows, etc.).

There is nothing new about these mechanisms. They apply to most branches of science. The tough feature about forestry is the great difficulty in their implementation because:

(a) There is such a great shortage of Canada PhD's in forestry available for hire.

(b) Discretionary funds and space are very scarce.

(c) There are few established scientists accessible (geographically or fiscally) to the schools.

(d) Several tenured "one-man deep" professorships in key subject areas of forestry are not, or only marginally, involved in forest research. Scientific development in these key areas is thus effectively blocked.

7. NSERC Recognition of Forestry Problems:

(a) NSERC apparently sees that it has obligation to build scientific excellence as well as support established excellence. Dr. Ingraham indicated at the December, 1980 Ottawa meeting to review forestry applications, that they were "desperate for suggestions."

(b) NSERC is locked into its present budgeting and funding mechanism; change is slow and difficult. Modification of the present mechanism is the easiest route.

(c) Strategic grants are for "support or initiation, or acceleration of substantive projects of programs of identified areas of national concern". Forestry is yet to be "Identified". If it was, who could use this type of grant? Only holders of operating grants. Given the rigour of the review system only a handfull of forestry professors could be eligible. Such a mechanism builds on strength.

(d) Post Docs $(\$ 18,000)$ University Research Fellowships (URF) $(\$ 24,150)$ are not very effective in assisting forestry when there are scarcely any Canadian PhD's produced in Forestry and the employment demand, at much higher salaries $(\$ 35,000)$ is so great. They are attractive to foreign PhD's - but there few labs suitable in Canadian forestry schools for Post Docs. The whole concept of URF's + a holding position in Universities for PHD's awaiting professional retirements really does not apply to forestry.

(e) The establishment of "Institutes" at Forestry schools has been proposed, such institutes cannot be supported totally by NSERC; only some operating and equipment money may be attracted, if the scientists have academic appointments. To make such an institute work a solid base of government and/or industrial funding is necessary.

8. It should be noted that many, if not most, of the biological scientists at Canadian Universities have a tougher funding situation than forestry professors; most must rely entirely on NSERC - in fact many top scientists are nearly totally dependent. Foresters and the agriculture types have some access to contracts, etc.
Moaning and groaning by Forestry Schools over lack of NSERC support is likely to antagonize. As far as support of excellence is concerned it has a hollow ring. The only case is for building excellence by NSERC at the forestry schools. The question is how can this be done, given present institutional constraints? I do not see any easy answers without a change in the "system".

9. The mechanism of budgeting of NSERC Committees should be noted. Renewals are built-in, with inflation. A very limited amount is budgeted for new applicants, thus there is little flexibility to increase funding of applicants. The pressures to reject or reduce applications is very great; for this Committee only $40 \%$ of the requested amount was budgeted.

10. I do not see that basic and applied proposals do not get equal treatment. Equipment and technique development applicants have been well funded - if they are qualified and publishing.

11. Forest science at the forestry schools requires "building". The precedent is Canadian Oceanography which has and is being deliberately supported through NSERC by the combined use of Core Grants ("For maintenance and operating costs of major research facilities which would not otherwise be supportable in Canada") and Strategic Grants ("Initiation or acceleration of substantial projects or programs in certain identified areas of national concern"). However it appears that there must be a nucleous of holders of operating grant holders, furthermore there must be agreement between them to work on a common programme and to interact as a group. Of the Canadian Forestry Schools, UBC and Laval are the only ones in this 'start position' today. Laval's group on mycorrhizae (Fortin et al) is very impressive and is spreading to $U$ of $T$ by Coop grants. Photogrammetry is well established.

12. NSERC has set-up a rigorous, expensive, competent, ponderous, and relatively inflexible grant system. It is tied-in to a low-level of council funding.

The sad, illogical and even absurd feature is that at the committee level an enormous effort is spent by about 300 professors to give away peanut sized grants while coconut sized contracts are given for often the same work by other Government Departments, with much less, or even no, rigorous review.

Again and again in the committee sessions well established scientists in Universities are granted actual reductions in funding because the money is just not available.

13. Canada has seen, what appears to be, a deliberate move by the Federal Government to reduce science in Canada in the last fifteen years. The process is still ongoing. My impression is that it is on its knees, even with massive funding increases there will be little or no recovery before the turn of the century.

The decline in the Canadian Forestry Service Research capability has resulted in expansion of Provincial forest research effort. One move that is logical is for the Provinces to fund the remaining forest scientists in the Federal labs with contracts. The BC Forest Service has already started this.

The wretched state of forest science at the Universities will also require Provincial action. However, a granting mechanism with rigorous review is required - the NSERC pattern could be followed. The present departmentally controlled contracting mechanism, suffers from three faults:

(i) Lack of rigorous anonymous review.

(ii) Uncertain annual funding -3 years is needed. 
(iii) Constraints of bureaucratic departmental approval.

Provincial granting for forest science could 'tie-into' ongoing department programmes: the national standard is set by NSERC - they should meet it. Industrial and government advice should be limited to policy, budgets and support areas. Project approval should be by scientists (government, industry and university).

14. The Federal policy of contracting out research through the Department of Supply and Services (DSS) involves great sums of money. It has been in effect for a number of years. It has turned some good Federal scientists into administrators. The contracts (I have had some) are often awarded with great speed and with little or no review. The required reports are often not published in journals, and may not be published at all. Some of the programmes, ENFOR for example, have produced some good work, but a lot has the appearance of a pork barrel for consultants. By policy businesses are given preference. Professors can collect salary supplements for contracts. They cannot collect from grants. With wretchedly low junior professor salaries $(\$ 22,000$ Associate Professor) as compared to high $(\$ 25-27,000)$ starting salaries for BScF graduates, the most desirable combination for the junior professor is a mix of both NSERC grants and contracts if he or she can get them. The greatest financial rewards are for doing the most applied work with the least review. When combined with consulting opportunities, the relative positions of grant research and the other options for professors have conflicting priorities. The lack of Canadian students looking for PhD's in forestry is understandable.

15. The dedication and very hard work by university scientists in biology working on basic research is very impressive. The excitement and enthusiasm of graduate students and professors that I saw on "site visits" to Universities across Canada was heartening. The fine facilities of the Food and Agriculture Faculties contrasted sharply with the rabbit warrens and cramped quarters of the Botany, Zoology and Forestry Departments. The involvement of agribusiness in supporting agriculture contrasted sharply with the almost total absence of forestry industry support for forestry.

16. Considering the vast contribution of the forest industry to the economy $(\$ 100,000,000$ Direct 1979$)$ the almost total absence of any forestry industry research is very sad. Paprican, Montreal is currently assessing industries need in silviculture research. A report will be issued in 1981 based on the views of 12 non-industry scientists from across Canada. A two day workshop was held to discuss recommendations and institutional mechanisms. One obvious mechanism is for the forest industry to support forest science in the Universities (Paprican did this by grants, not contracts, in the 1960 's). Due to Provincial forest policy changes giving forest management responsibility to licencees, and due to proposed Federal incentives for industrial research, the circumstances are ripe for more industrial research in growing forests.

17. At the time of printing this article, NSERC announced a forestry development fund which will provide about $\$ 80,000$. for each of the six forestry schools in the 1982 fiscal year.

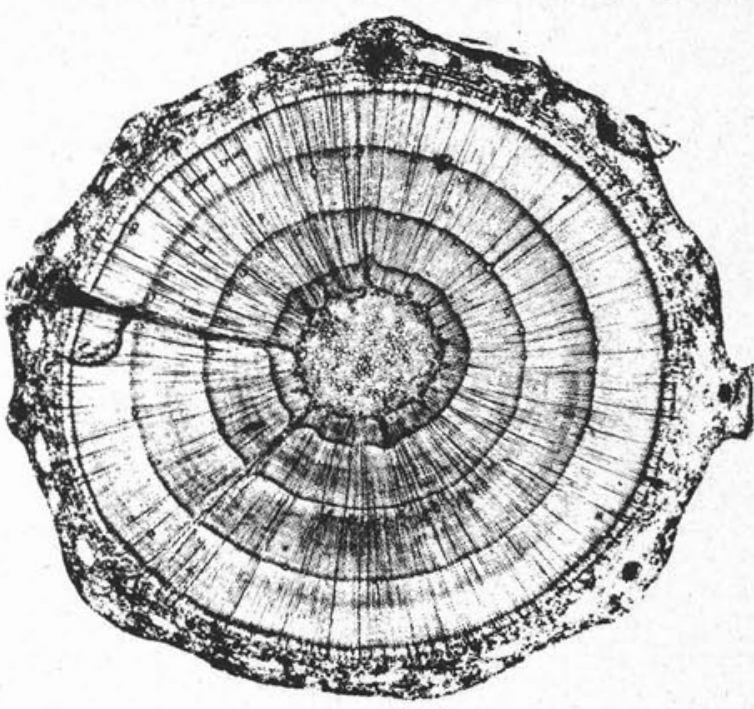

Canadian Woods

THEIR PROPERTIES AND USES

\section{THIRD EDITION EDITED BY E.J. MULLINS \&}

\section{T.S. McKNIGHT}

This edition of Canadian Woods presents a comprehensive overview of the multi-faceted forest industry in a completely revised and expanded format. This first revision since 1951 will serve as the primary reference for years to come. Lavishly illustrated with more than $\mathbf{2 8 0}$ photographs and drawings, it is an important addition to the library of students, teachers, and practitioners. $\$ 27.50$

\section{Contents include}

- the woods found in Canada and their commercial uses

- the strength, physical properties, and chemistry of wood

- lumber production, wood drying, and wood protection

- glues and gluing

- the use of wood and wood products

- panel products, houses, and structures

- pulp and paper

- residues

- codes and standards

- trends and projections for the future

UNIVERSITY OF TORONTO PRESS 